\title{
Preparation of Porous Silica Materials via Sol-Gel Nanocasting of Nonionic Surfactants: A Mechanistic Study on the Self-Aggregation of Amphiphiles for the Precise Prediction of the Mesopore Size
}

\author{
Bernd Smarsly,* Sebastian Polarz, ${ }^{*, \dagger}$ and Markus Antonietti \\ Max-Planck Institute of Colloids and Interfaces, D-14424 Potsdam, Germany
}

Received: May 17, 2001; In Final Form: August 20, 2001

\begin{abstract}
Sol-gel nanocasting is used to imprint the soft-matter structures of lyotropic phases of nonionic $n$-alkylpoly(ethylene oxide) amphiphiles (" $\mathrm{C}_{x} \mathrm{E}_{y}$ ") into solid porous silica. Small angle X-ray scattering (SAXS), nitrogen sorption, and transmission electron microscopy (TEM) are used to investigate the dependence of the porosity on the block lengths or the block volumes, respectively. It is found that the size of the mesopores is a function of the lengths/volumes of both the alkyl chain $\left(N_{\mathrm{A}}\right)$ and the PEO block $\left(N_{\mathrm{B}}\right)$. Moreover, the materials contain a substantial degree of additional microporosity. A quantitative model is developed that relates the amphiphile organization during the nanocasting to the size of the mesopores and the microporosity. In particular, it turns out that depending on the number of EO units a fraction of the PEO chains contributes to the mesoporosity, while a significant portion leads to additional micropores. This model provides a quantitative description of the distribution of the hydrophobic and hydrophilic blocks within the lyotropic phase itself. Our findings indicate that the interface areas $b^{2}$ of single surfactant chains are a function of the block lengths, which can be described by a scaling law $b^{2} \propto N_{\mathrm{A}}{ }^{0}{ }^{16} N_{\mathrm{B}}{ }^{04}$. Mixtures of chemically equivalent amphiphiles with different block ratios are studied in further detail. It is seen that every pore size between the size originating from the "parent" templates can be adjusted simply by mixing various amounts of two surfactants, proving that true mixed phases act as a template for the silica pores.
\end{abstract}

\section{Introduction}

The work of Beck, Vartuli, Kresge et al. in 1992 about the preparation of the first ordered mesoporous silica materials ${ }^{1,2}$ by templating of surfactant aggregates created an unparalleled research development toward novel porous oxidic materials. Applications of mesoporous oxides are found in the fields of catalysis, chemical sensing, and separation or as "nanoreactors". ${ }^{3-9}$

In the case of the MCM-41-like materials, the hydrolysis of a silica precursor in low-concentrated surfactant solutions leads to a precipitation of hexagonal (MCM-41) or cubic (MCM-48) porous silicas as micron-sized powders. Mechanistic studies on the formation of these systems have provided a quite detailed mechanistic knowledge. ${ }^{10-13}$ Either the silica is formed in the water-containing domains of a preformed liquid crystal or the silica precursor itself, via a cooperative interaction with the surfactant, forms an ordered phase which then is solidified.

The second way of templating starts with concentrated aqueous dispersions of amphiphiles (in most cases nonionic surfactants and block copolymers). This approach was introduced and extended by Göltner et al. ${ }^{14-19}$ She termed the whole procedure "nanocasting", because a liquid-crystalline phase formed by the amphiphilic block copolymers in water is fixed (usually under preservation of the phase structure) by the solgel formation of silica in the hydrophilic domains, thus resulting

† E-mail: polarz@mpikg-golm.mpg.de. Fax: (+49)-331-567 9502. in a solid 1:1 replica. Recently, also Stucky, Melosh, Chmelka et al. applied the nanocasting concept to prepare hexagonal mesoporous silica with Pluronics (PEO-PPO-PEO block copolymers) as templates..$^{20,21}$ As major advantages, the nanocasting provides the predictability of the structure and offers the possibility to prepare macroscopic porous objects (monoliths). However, the mechanism of the nanocasting was not investigated as extensively as the MCM synthesis, although this method is used more and more often.

In many cases, the block copolymers used for the nanocasting contain poly(ethylene oxide) as the hydrophilic block. It was recently shown that the PEO block leads to an (generally undesired) additional microporosity (pore size below $2 \mathrm{~nm}$ according to IUPAC), ${ }^{22,23}$ because a certain fraction of the PEO chains is tightly embedded inside the silica walls as a consequence of the "molecular" templating of single PEO chains. ${ }^{21,24-27}$ Hence, the removal of the block copolymer by calcination or suitable extraction procedures leads to a material with mesopores as well as micropores, the size of the latter is determined by the diameter of single PEO chains. In this picture, the hybrid material would consist of the hydrophobic core and the silica phase containing the PEO chains (thus termed the "two-phase model"). In conclusion, it turned out that the additional microporosity might be a general feature of porous inorganics obtained from PEO-containing block copolymers used as a template. This interpretation is supported by recent NMR studies of de Paul et al. on the mobility of PEO chains of the 
amphiphilic block copolymer poly(isoprene- $b$-ethylene oxide) embedded in an inorganic matrix that was obtained via a solgel process. ${ }^{28}$ As a result, it was shown that the inorganic phase and PEO are intimately mixed on a molecular level. However, concerning the distribution of PEO within the organic-inorganic hybrid material, a different model has already been developed. ${ }^{29}$ A part of the PEO chains may form a separate "phase" between the hydrophobic block and the silica phase, which was therefore termed the "three-phase model". Within the scope of this model, it was assumed that this PEO phase contributes to the mesoporosity. The current paper is aimed at a more quantitative understanding of both the formation of microporosity and the factors determining the pore sizes in the formation of mesoporous silica materials by the nanocasting procedure. As porogens, we used the well-known nonionic $n$-alkyl-poly(ethylene oxide) surfactants (" $\mathrm{C}_{x} \mathrm{E}_{y}$ "-types), as previously employed by Pinnavaia et al. ${ }^{30-34}$ and Attard and Göltner ${ }^{14}$ to produce porous silica materials. In particular, the influence of the alkyl and PEO chain lengths on the micro- and mesoporosity is subject to closer investigation by means of transmission electron microscopy (TEM), nitrogen sorption, and small-angle X-ray scattering (SAXS). The systematic variation of the relative chain lengths of both blocks allowed us to study the structure of the mesoporous silica with dependence on surfactant characteristics. A semiquantitative model is developed to relate the mesopore sizes and the degree of microporosity to the ratio between the lengths of the alkyl chain and the PEO block.

A further important aspect of templating strategies is the control of the mesopore size by suitable methods. Attempts to influence the size of the silica mesopores have been so far focused on swelling the lyotropic liquid crystals with certain additives ${ }^{35,36}$ or the use of block copolymers with variable size. Instead, we present a different strategy by which the mesopore size can be controlled by mixing block copolymers or surfactants of different chain lengths.

\section{Materials and Methods}

2.1. Materials. The SE-type block copolymers were obtained from Goldschmidt. All other precursors were obtained from Aldrich and have been used without further purification. The porous silica materials were prepared as follows: A $1 \mathrm{~g}$ sample of the block copolymer (or a 1:1 mixture) is dissolved in $1 \mathrm{~g}$ of aqueous hydrochloric acid $(\mathrm{pH}=2)$ under slight heating. Then $2 \mathrm{~g}$ of TEOS is added. Homogenization occurs in some minutes. The evolving ethanol is removed in a vacuum. The resulting viscous solutions or gels were aged at $60{ }^{\circ} \mathrm{C}$ in a drying oven for 3 days. The organic template is removed via calcination in air at $550{ }^{\circ} \mathrm{C}$ for $5 \mathrm{~h}$.

2.2. Measurements. Transmission electron microscopy (TEM) images were acquired on a Zeiss EM $912 \Omega$ at an acceleration voltage of $120 \mathrm{kV}$. Samples were ground in a ball mill and taken up in acetone. One droplet of the suspension was applied to a 400 mesh carbon-coated copper grid and left to dry in air. Nitrogen sorption data were obtained with a Micromeritics Tristar instrument. Small-angle X-ray scattering (SAXS) curves were recorded by means of a Kratky camera and also a rotating anode with pinhole collimation. A Nonius rotating anode device $(P=4 \mathrm{~kW}, \mathrm{Cu} \mathrm{K} \alpha)$ and an image-plate detector system were used. With the image plates placed at a distance of $40 \mathrm{~cm}$ from the sample, a scattering vector range from $s=0.05-1.6 \mathrm{~nm}^{-1}$ $(s=2 / \lambda \sin \theta)$ was available. The samples were irradiated for $18 \mathrm{~h}$ to reduce the noise level and to obtain a sufficiently high scattering intensity. The 2D isotropic diffraction patterns were transformed into a 1D radial average of the scattering intensity.

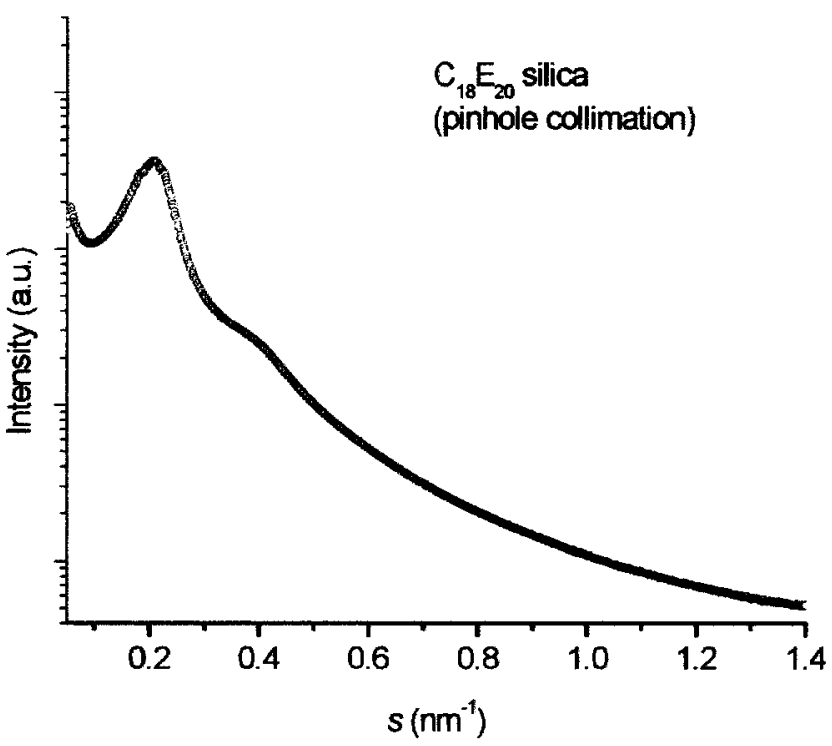

Figure 1. SAXS curve (point focus) of the $\mathrm{C}_{12} \mathrm{E}_{20}$ silica a representative example of the SAXS patterns of the $\mathrm{C}_{x} \mathrm{E}_{y}$ silicas.

2.3. Evaluation of SAXS Data. Small-angle scattering has turned out to be a powerful technique to investigate the structure two-phase systems (i.e., nanostructure materials that can be supposed to be composed of two domains of constant electron density (SAXS) or scattering length density (SANS)). A suitable approach to characterize porous materials is based on the evaluation of the so-called "chord-length distribution" (CLD) $g(r)$, which was previously introduced by Méring and Tchoubar and which can be calculated from small-angle scattering data. ${ }^{37-39}$

The CLD represents a quantitative statistical description for the distances connecting phase boundaries in a two-phase system with sharp phase boundaries. The determination of the CLD is highly desirable, as it provides useful information, such as the average pore size, prevalent length scales, and the specific surface area. In particular, if the pore structure cannot be attributed to a well-defined macrolattice, the determination of chord-length distributions is an appropriate analytical way for the characterization especially of disordered and weakly ordered materials. The specific surface area per volume $S / V$ is directly related to the average chord length ("Porod length") $l_{\mathrm{p}} \cdot{ }^{40-42}$

$$
l_{\mathrm{p}}=4 \phi(1-\phi) \frac{V}{S}
$$

where $\phi$ is the volume fraction of one of the two phases. $l_{\mathrm{p}}$ is the first moment of the CLD and is related to the average chord lengths $l_{i}$ of the two constituent phases by

$$
\frac{1}{l_{\mathrm{p}}}=\frac{1}{l_{1}}+\frac{1}{l_{2}}=\frac{1}{\phi_{1} l_{2}}=\frac{1}{\phi_{2} l_{1}}
$$

If the experimental SAXS setup covers a sufficiently large range of the scattering vector $\mathbf{s}$, the chord-length distribution provides a complete characterization of the pore structure (in real space) including structural units of substantially different sizes. The latter is a precondition to determine both micropores and mesopores in one single sample of porous silica.

Figure 1 shows a typical SAXS pattern of $\mathrm{C}_{x} \mathrm{E}_{y}$ silicas, recorded by means of a rotating anode device. The $I(s)$ curve clearly shows a marked interference peak at $s \approx 0.2 \mathrm{~nm}^{-1}$ and a second shoulder at $s \approx 0.4 \mathrm{~nm}^{-1}$, which correspond to the packing of the wormlike pores into a certain distorted 3D 
TABLE 1: Mesopore Sizes of Various $C_{x} E_{y}$ Silicas $^{a}$

\begin{tabular}{|c|c|c|c|c|c|c|}
\hline \multirow[b]{2}{*}{ sample name } & \multicolumn{5}{|c|}{ mesopore size } & \multirow{2}{*}{$\begin{array}{l}\text { specific surface } \\
\text { area }\left(\mathrm{m}^{2} / \mathrm{g}\right)(\mathrm{BET})\end{array}$} \\
\hline & DFT & $\mathrm{BJH}$ ads & BJH des & Harkins-Jura & $\overline{\text { TEM }}$ & \\
\hline Brij $35\left(\mathrm{C}_{12} \mathrm{E}_{30}\right)$ & 3.3 & 2.79 & 2.82 & 2.7 & 2.7 & 977 \\
\hline Brij $78\left(\mathrm{C}_{18} \mathrm{E}_{20}\right)$ & 3.7 & 3.11 & 3.04 & 3.3 & 3.1 & 973 \\
\hline Brij 56( $\left.\mathrm{C}_{16} \mathrm{E}_{10}\right)$ & 3.5 & 2.89 & 2.84 & 2.9 & n.a. & 1144 \\
\hline $\mathrm{C}_{12} \mathrm{E}_{8}$ & 2.7 & 2.51 & 2.52 & 3.3 & 2.8 & 1204 \\
\hline $\mathrm{C}_{8} \mathrm{E}_{4}$ & 2.2 & $(2.3)_{\text {microporous }}$ & $(2.4)_{\text {microporous }}$ & microporous & n.a. & 1242 \\
\hline $\mathrm{C}_{16} \mathrm{E}_{8}$ & 3.1 & 2.54 & 2.52 & 2.6 & n.a. & 1218 \\
\hline $\mathrm{C}_{12} \mathrm{E}_{4}$ & 2.7 & 2.42 & 2.42 & n.a. & n.a. & 1275 \\
\hline Brij $35+78\left(\mathrm{C}_{12} \mathrm{E}_{30}+\mathrm{C}_{18} \mathrm{E}_{20}\right)$ & 3.5 & 2.92 & 2.86 & 3 & 2.8 & 884 \\
\hline Brij $35+56\left(\mathrm{C}_{12} \mathrm{E}_{30}+\mathrm{C}_{16} \mathrm{E}_{10}\right)$ & 4.2 & 2.99 & 2.95 & 3.5 & n.a. & 800 \\
\hline Brij $56+78\left(\mathrm{C}_{16} \mathrm{E}_{10}+\mathrm{C}_{18} \mathrm{E}_{20}\right)$ & 3.6 & 3.05 & 2.94 & 3.1 & n.a. & 1025 \\
\hline Brij $56\left(\mathrm{C}_{16} \mathrm{E}_{10}\right)+\mathrm{C}_{12} \mathrm{E}_{8}$ & 2.9 & 2.58 & 2.56 & 3.1 & n.a. & 1106 \\
\hline Brij $78\left(\mathrm{C}_{18} \mathrm{E}_{20}\right)+\mathrm{C}_{12} \mathrm{E}_{8}$ & 3.0 & 2.6 & 2.59 & 2.5 & n.a. & 1003 \\
\hline Brij $78\left(\mathrm{C}_{18} \mathrm{E}_{20}\right)+\mathrm{C}_{8} \mathrm{E}_{4}$ & 3.0 & 2.6 & 2.64 & 2.4 & 2.6 & 1133 \\
\hline Brij $35\left(\mathrm{C}_{12} \mathrm{E}_{30}\right)+\mathrm{C}_{16} \mathrm{E}_{8}$ & 3.3 & 2.7 & 2.7 & 2.7 & n.a. & 980 \\
\hline $\mathrm{C}_{16} \mathrm{E}_{8}+\mathrm{C}_{8} \mathrm{E}_{4}$ & 2.8 & 2.42 & 2.41 & 1.8 & n.a. & 1143 \\
\hline $\mathrm{C}_{16} \mathrm{E}_{8}+\mathrm{C}_{12} \mathrm{E}_{8}$ & 2.8 & 2.65 & 2.73 & 2.1 & n.a. & 1228 \\
\hline Brij $35\left(\mathrm{C}_{12} \mathrm{E}_{30}\right)+\mathrm{C}_{12} \mathrm{E}_{8}$ & $(2.8)_{\text {demixed }}$ & $(2.87)$ & $(2.91)$ & n.a. & n.a. & (772) \\
\hline Brij $35\left(\mathrm{C}_{12} \mathrm{E}_{30}\right)+\mathrm{C}_{12} \mathrm{E}_{4}$ & $(2.9)_{\text {demixed }}$ & (2.79) & $(2.81)$ & n.a. & n.a. & $(895)$ \\
\hline Brij $56\left(C_{16} E_{10}\right)+C_{8} E_{4}$ & 2.8 & 2.6 & 2.6 & n.a. & n.a. & 1102 \\
\hline Brij $35\left(\mathrm{C}_{12} \mathrm{E}_{30}\right)+\mathrm{C}_{8} \mathrm{E}_{4}$ & 2.6 & $(2.4)_{\text {microporous }}$ & $(2.4)_{\text {microporous }}$ & n.a. & n.a. & 972 \\
\hline $\mathrm{C}_{12} \mathrm{E}_{8}+\mathrm{C}_{8} \mathrm{E}_{4}$ & 2.4 & $(2.3)_{\text {microporous }}$ & $(2.3)_{\text {microporous }}$ & n.a. & n.a. & 1408 \\
\hline Brij $96\left(C_{18} E_{10}\right)+C_{8} E_{4}$ & 2.7 & 2.5 & 2.45 & n.a. & n.a. & 981 \\
\hline Brij $30\left(\mathrm{C}_{12} \mathrm{E}_{4}\right)+\mathrm{C}_{8} \mathrm{E}_{4}$ & 2.2 & $(2.4)_{\text {microporous }}$ & $(2.4)_{\text {microporous }}$ & n.a. & n.a. & 1321 \\
\hline Brij $30\left(\mathrm{C}_{12} \mathrm{E}_{4}\right)+\mathrm{C}_{12} \mathrm{E}_{8}$ & 3.4 & 2.7 & n.a. & n.a. & n.a. & 1310 \\
\hline
\end{tabular}

${ }^{a}$ In several cases the analysis of TEM pictures did not provide reliable values for the mesopore size. The samples.

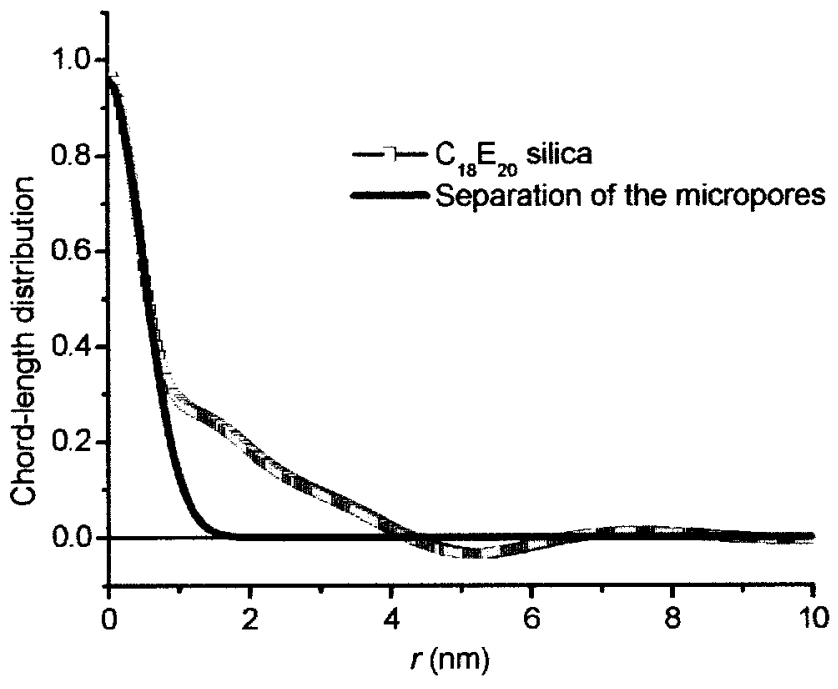

Figure 2. Chord-length distribution of the $\mathrm{C}_{18} \mathrm{E}_{20}$ silica as a representative example of the $\mathrm{C}_{x} \mathrm{E}_{y}$ silicas. The large contribution at small length scales below $1 \mathrm{~nm}$ has to be interpretated as a consequence of the presence of a large degree of microporosity.

alignment. Since the low number of interference peaks does not allow a fitting of the SAXS curve in terms of a certain pore morphology and a well-defined macrolattice (hexagonal, cubic, etc.), the concept of the CLD turned out to be the most appropriate method to evaluate the SAXS data quantitatively, in particular with respect to the presence of micropores.

Figure 2 shows the chord-length distribution $g(r)$ of the $\mathrm{C}_{18} \mathrm{E}_{20}$ silica, the CLDs of the other $\mathrm{C}_{x} \mathrm{E}_{y}$ silicas are similar. The evaluation of these CLDs provides a suitable description of the pore structure and reveals interesting features. All of the CLDs show a pronounced contribution at small length scales below approximately $1 \mathrm{~nm}$. According to Ciccariello et al., a value of $g(0)>0$ is indicative of angular structures (edges, vertexes). ${ }^{43-45}$

The behavior of the CLD at larger $r$ is related to the size and shape of the mesopores and their spatial distribution. Since the mesopore sizes were determined by nitrogen sorption, the evaluation of the CLD was primarily used to investigate the microporous character of these silicas.

In principle, it is not possible to determine pore size distributions and the wall thickness directly from the CLD without further assumptions, as the CLD is a complex superposition of the distributions of chords within both phases and chords penetrating the phases. However, taking into account the analysis of TEM images and sorption data, the behavior of the CLD at small length scales $r$ has to be attributed to a large abundance of micropores. Moreover, recent experiments on porous silicas obtained from nanocasting of poly(styrene)poly(ethylene oxide) provided a direct support of this interpretation using a combination of SANS and nitrogen sorption. ${ }^{46}$ Apart from this qualitative evidence of micropores, the CLDs also allow us to estimate the microporosity in terms of the specific surface area and the pore size. Assuming that the position of micropores and mesopores are uncorrelated (i.e., the micropores are randomly distributed in the silica matrix), the chord-length distribution of the micropores can be separated from the rest of the CLD, thus providing an average chord length $l_{\text {micropore }}$ of the micropores. This procedure then allows us to evaluate an average size of the micropores and also to estimate their contribution to the overall specific surface area. It can be shown that

$$
\frac{S_{\text {micropore }}}{S}=\frac{l_{\mathrm{p}}}{l_{\text {micropore }}} \frac{\phi_{\text {micropore }}\left(1-\phi_{\text {micropore }}\right)}{\phi(1-\phi)}
$$

if the mesopores and microppores are sufficiently different in size and if the micropores and mesopores are not spatially correlated. $\phi$ is taken from the $\mathrm{N}_{2}$ sorption measurements under the assumption of cylindrical micropores. By this method one finally obtains the surface area of the micropores as well as an estimation of the micropore size by relating $l_{\text {micropore }}$ to certain geometries such as cylinders, spheres, etc. Assuming a cylindrical morphology, the micropore diameter turned out to be about $0.7 \mathrm{~nm}$. For sufficiently long cylinders the surface area, the 

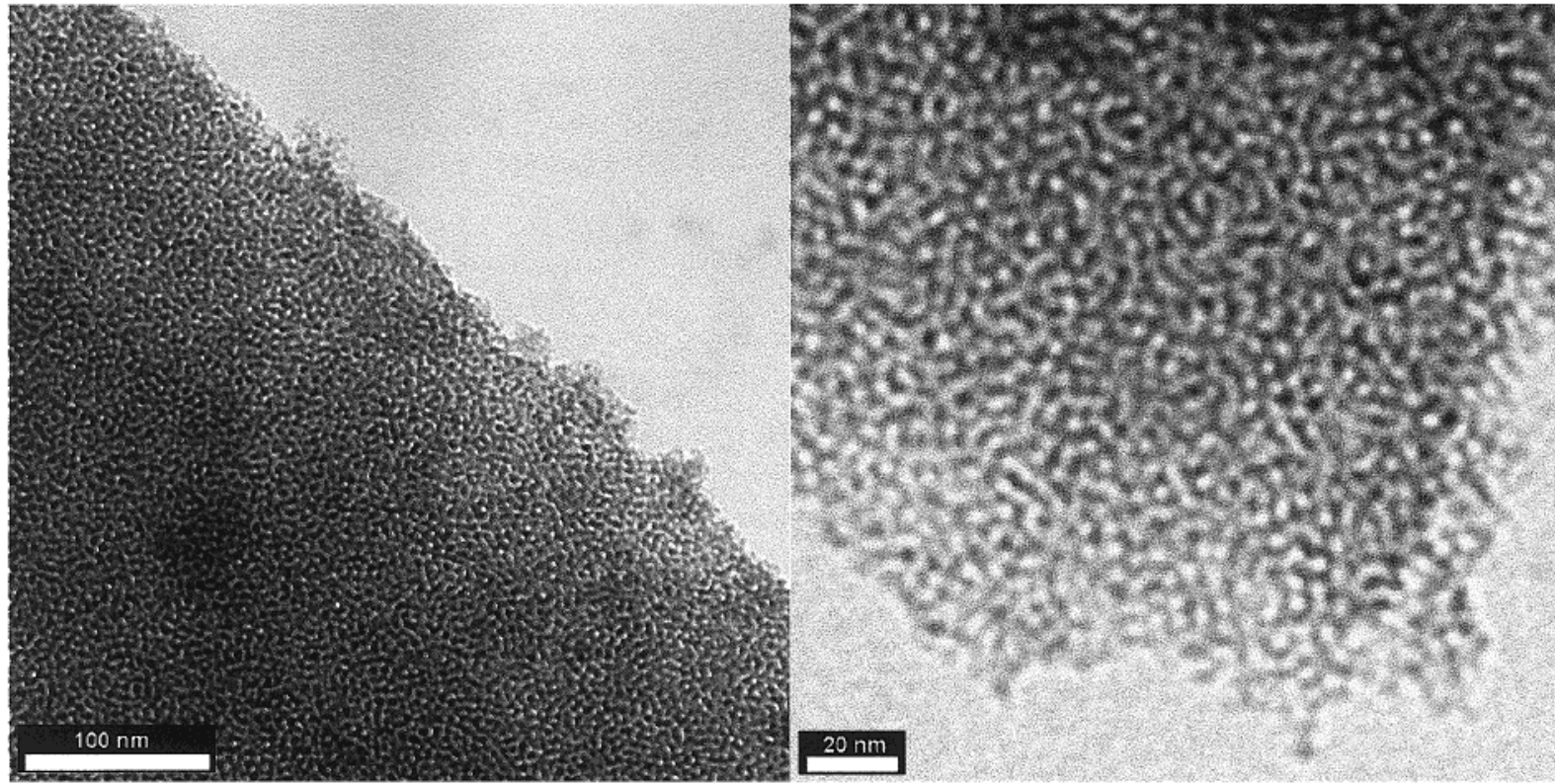

Figure 3. TEM images of representative $\mathrm{C}_{x} \mathrm{E}_{y}$-based silica materials derived via nanocasting. (Two magnifications are shown).

TABLE 2: $\mathbf{N}_{2}$ Pore Volume and SAXS Micropore Analysis Data

\begin{tabular}{ccccc}
\hline template & $D_{\text {micropore }}(\mathrm{nm})$ & $V_{\text {micro }}\left(\mathrm{cm}^{3} / \mathrm{g}\right)$ & $V_{\text {tot }}\left(\mathrm{cm}^{3} / \mathrm{g}\right)$ & $S_{\text {micro }} / S_{\text {tot }}$ \\
\hline $\mathrm{C}_{12} \mathrm{E}_{30}$ & 0.5 & 0.08 & 0.7 & 0.6 \\
$\mathrm{C}_{12} \mathrm{E}_{8}$ & 0.6 & 0.14 & 0.64 & 0.8 \\
$\mathrm{C}_{18} \mathrm{E}_{20}$ & 0.7 & 0.10 & 0.88 & 0.8 \\
$\mathrm{C}_{16} \mathrm{E}_{10}$ & 0.7 & 0.11 & 0.89 & 0.70 \\
$\mathrm{C}_{16} \mathrm{E}_{8}$ & 0.7 & 0.09 & 0.9 & 0.7 \\
$\mathrm{C}_{8} \mathrm{E}_{4}$ & 0.6 & 0.10 & 0.56 & 0.70
\end{tabular}

volume and the diameter are related to each other by $D_{\text {micropore }}$ $=4 V_{\text {micropore }} / S_{\text {micropore }}$. The data for the various $\mathrm{C}_{x} \mathrm{E}_{y}$ silicas are given in Table 2 .

\section{Mechanistic Study}

3.1. Investigation of the Porosity. For a systematic study of the nanocasting in detail, i.e., the relation between the micelle and pore architecture, a large variety of chemically equivalent block copolymers with different block lengths have to be used. Moreover, it has to be assured that their lyotropic phases (and, hence, the corresponding pore structure) are independent of the block lengths. This can be realized by an appropriate choice of a set of $n$-alkyl-oligo(ethylene oxide) $\left(\mathrm{C}_{x} \mathrm{E}_{y}\right)$ surfactants. The lyotropic phase behavior of this type of surfactants is wellknown for a large number of $\mathrm{C}_{x} \mathrm{E}_{y}$ compounds. ${ }^{47}$ With concentrations of 50 wt $\%$, all of the $\mathrm{C}_{x} \mathrm{E}_{y}$ lyotropic phases show a hexagonal morphology according to previous studies. The silicas obtained by nanocasting of $\mathrm{C}_{x} \mathrm{E}_{y}$ surfactants possess less ordered mesopores in a distorted hexagonal morphology according to TEM (Figure 3) and SAXS and as also reported in the literature. ${ }^{31,33,34}$ In all cases "worm-type" pore morphologies have been obtained, and the order of the structures was not affected by different block lengths of the surfactants in the chosen range, as revealed by SAXS and TEM. The question arises, what are the reasons for the less ordered pores in the silica? Polydispersity of the amphiphiles can be eliminated as one alternative due to two reasons. Besides the commercially available Brij surfactants (which had relatively low polydispersities according to GPC analysis between 1.05 and 1.1), we also used several pure oligoglycol $n$-alkyl amphiphiles $\left(\mathrm{C}_{12} \mathrm{E}_{4}, \mathrm{C}_{8} \mathrm{E}_{4}\right.$, $\mathrm{C}_{16} \mathrm{E}_{8}, \mathrm{C}_{12} \mathrm{E}_{4}$ ) where no polydispersity is present. In all cases the "worm-type" morphology was observed. We explain the lower order of the pore systems by a distortion of the cylindrical phase by the occurrence of ethanol during the nanocasting procedure and by the succeeding increase of viscosity of the solvent due to the proceeding sol-gel process that fixes the thermal movement of the lyotropic phase.

In the following the porosity is quantitatively described by the evaluation of small-angle X-ray scattering (SAXS) data, TEM, and sorption measurements. In particular, the microporosity was investigated by suitable and reliable evaluation methods for SAXS data, as the determination of micropores by nitrogen sorption may involve uncertainties. Because a quantitative TEM investigation of the mesopore sizes requires a statistical evaluation of the images, TEM measurements were only performed on a few samples. It was seen that the pore size does not differ significantly from the values derived by SAXS or sorption analysis.

Sorption isotherms of the most different samples (with respect to the block lengths), the $\mathrm{C}_{8} \mathrm{E}_{4}$ - and the $\mathrm{C}_{18} \mathrm{E}_{20}$-derived silica materials, and the corresponding pore-size distributions obtained from DFT theory ${ }^{48-50}$ are shown in Figure 4. ${ }^{51,52}$ The isotherm of $\mathrm{C}_{18} \mathrm{E}_{20}$ silica shows an explicit mesopore sorption behavior and is characterized by a small hysteresis pattern typical of small mesopores of 2-3 nm. Moreover, the large surface area itself is indicative of the presence of additional micropores. In contrast, the isotherm of $\mathrm{C}_{8} \mathrm{E}_{4}$ silica does not show a hysteresis loop and is characteristic of a porous material with a large degree of microporosity and also pores of about 2 nm. . $22,23,53^{2}$

Accordingly, a DFT analysis reveals that the average size of the (meso)pores of $\mathrm{C}_{18} \mathrm{E}_{20}$ is significantly larger than those of $\mathrm{C}_{8} \mathrm{E}_{4}$, which is in qualitative agreement with the assumption that the length of the hydrophobic block influences the mesopore size. To investigate the influence of the block lengths of the alkyl and PEO chains in a systematic way, all of the silicas obtained from $\mathrm{C}_{x} \mathrm{E}_{y}$ surfactants available to us and also silicas obtained from 1:1 mixtures of $\mathrm{C}_{x} \mathrm{E}_{y}$ surfactants were subject to a quantitative sorption analysis with regard to the mesopore sizes using different evaluation methods (DFT, BJH, Harkins-Jura). The data are summarized in Table 1. It is seen that a reasonable agreement is obtained between the different evaluation methods, 

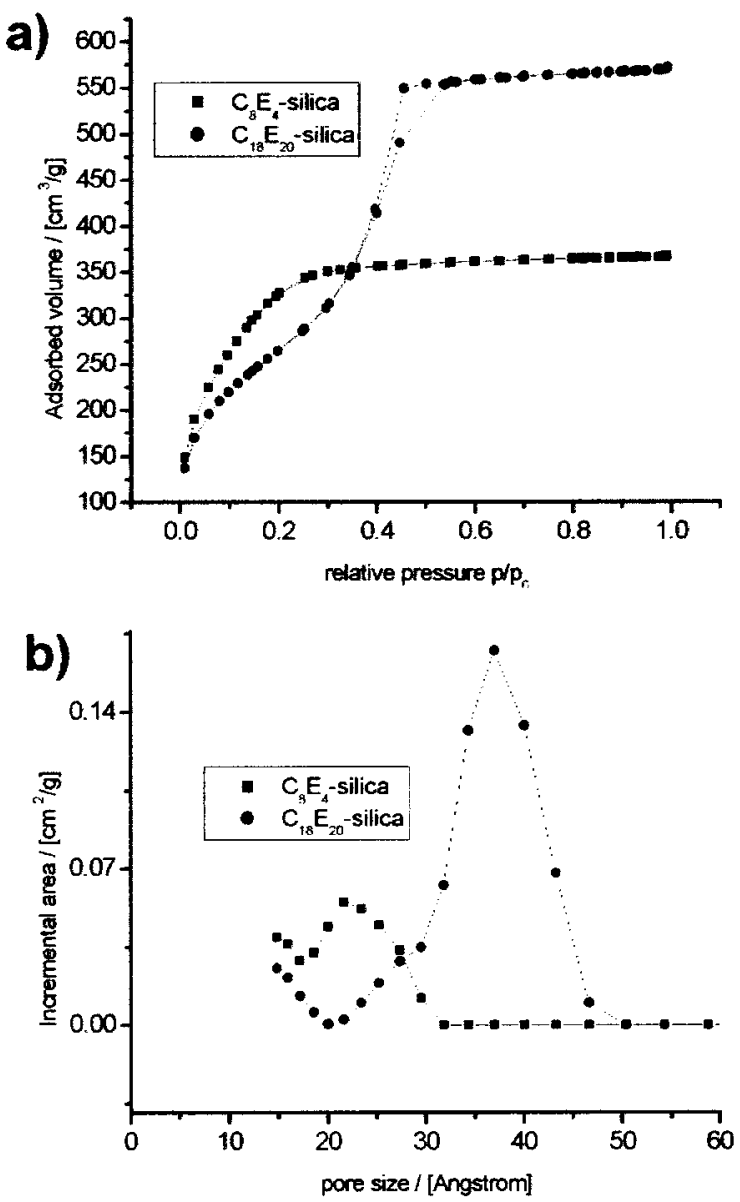

Figure 4. Isotherms and corresponding DFT-pore size distributions for $\mathrm{C}_{8} \mathrm{E}_{4}$ - and $\mathrm{C}_{18} \mathrm{E}_{20}$-derived silica materials.

thus providing a reliable method for the determination of mesopore sizes by sorption techniques. It has to be mentioned that the data show a systematic difference in the mesopore sizes determined by a DFT approach and the classical methods (BJH, Harkins-Jura) for one sample. However, up to now the development of methods to determine absolute values for mesopore sizes is still a matter of intensive research and beyond the scope of this study. Moreover, the data quality is sufficient to observe clear tendencies with respect to the mesopore sizes of different samples relative to each other. Since this study predominantly addresses only the relative changes in mesopore sizes as a function of the block lengths, the interpretation of the changes in absolute mesopore size is not intended. We have decided to take the DFT derived values for mesopore sizes for the further discussion, as the DFT approach has fundamental advantages compared to the classical evaluation methods.

In a classical picture water induces a microphase separation during sol-gel synthesis where the hydrophobic blocks are aggregated and build up a separate organic phase and the hydrophilic parts are dispersed in the aqueous medium and stabilizes the interface ("two-phase system"). In the resulting porous material only the volume of the hydrophobic phase determines the mesopore size. In this model, therefore, the mesopore diameters should depend on the length (or volume which is a function of the length) of the hydrophobic block. The experimental dependence of the pore diameter on the tail length is shown in Figure 5.

Obviously, the sorption data reveal a pronounced dependence of the mesopore sizes on the block lengths of the corresponding $\mathrm{C}_{x} \mathrm{E}_{y}$ surfactants. Indeed, the mesopore size increases with

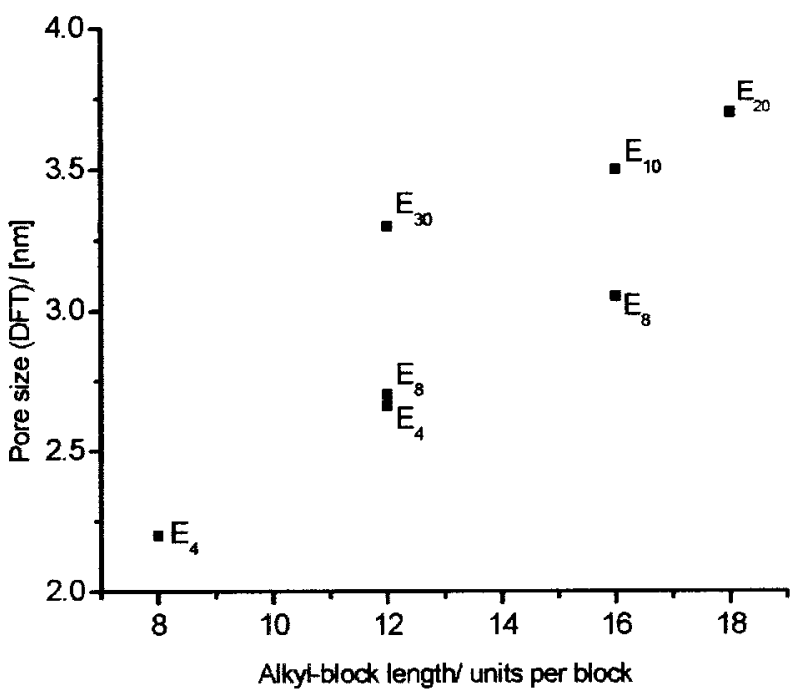

Figure 5. Dependence of the mesopore size (DFT values) as a function of the length of the hydrophobic blocks of $\mathrm{C}_{x} \mathrm{E}_{y}$ silicas.

increasing tail length. For the $\mathrm{C}_{8}$-derived silica material $\left(\mathrm{C}_{8} \mathrm{E}_{4}\right)$ a pore size of $2.2 \mathrm{~nm}$ was obtained. The pore size increases successively and reaches the largest value in this series for $\mathrm{C}_{18}\left(\mathrm{C}_{18} \mathrm{E}_{20}\right)$ with $3.7 \mathrm{~nm}$. In addition, these results indicate that a considerable part of the mesopore size is also due to the PEO corona, as the mesopore size also increases with the length of the PEO chain for constant alkyl chain length (e.g., see homologous series with $\mathrm{C}_{12}$ and $\mathrm{C}_{16}$ ). The diameter of the mesopores is in conformity with the molecular dimensions of the chain lengths, as determined by molecular modeling calculations.

Our data therefore question the validity of the "two-phase model" which is incompatible with the observation that the mesopore size considerably depends on the hydrophilic block. However, in a recent work it was already figured out that just a part of the PEO chains are located in the silica walls leading to additional microporosity. ${ }^{29}$ In this picture, the PEO chains that are not situated in the silica wall will, instead, contribute to the mesopore volume ("three phase model"). Obviously, a deeper knowledge of the distribution of PEO is essential to get more insights into the nanocasting mechanism and to learn about amphiphilic organization during the nanocasting. Because of this unclear relative distribution of PEO, additional experimental evidence is required for the quantitative description of mesopore formation in nanocasting procedures.

The dependence of the mesopore sizes upon $N_{\mathrm{A}}$ ( $\cong$ number of $-\mathrm{CH}_{2}$-units in the hydrophobic block) and $N_{\mathrm{B}}$ ( $\cong$ number of EO units in the hydrophilic block) is of particular interest (Figure $6)$.

It is seen that the pore size $D_{\mathrm{c}}$ depends significantly on the length of both blocks. A fit of the experimental values with a surface in the sense of a function $D_{\mathrm{c}}=f\left(N_{\mathrm{A}}, N_{\mathrm{B}}\right)$ delivers the empirical relation $D_{\mathrm{c}} \propto k_{\mathrm{A}} N_{\mathrm{A}}{ }^{04} \cdot k_{\mathrm{B}} N_{\mathrm{B}}{ }^{025}$, with $k_{\mathrm{A} / \mathrm{B}}$ as constants. The data show that the influence of the hydrophobic block on the mesopore size is higher as for the PEO block. This relation already allows the prediction of pore sizes when the block length is varied; that is, new porous systems can be tailormade in a controlled fashion, which is important for material science when high precision pore control or pore design is required.

However, to gain an understanding about the nanocasting and amphiphile organization the empirically found dependencies have to be explained by a physically reasonable model. 


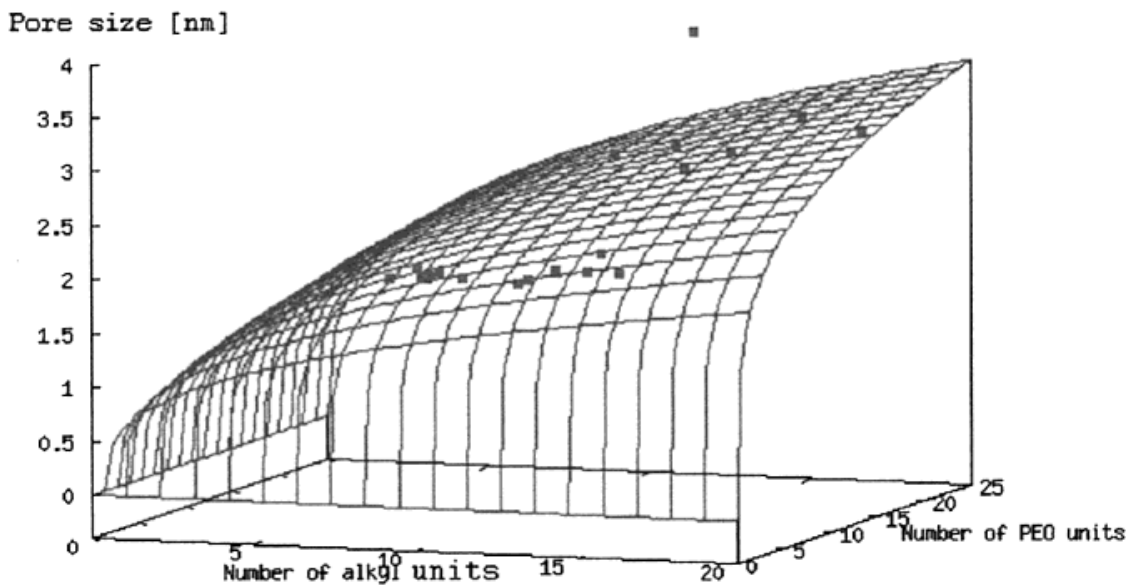

Figure 6. Empirically determined surface for the dependence of the pore diameter as a function of both blocks $D_{\mathrm{c}}=f\left(N_{\mathrm{A}}, N_{\mathrm{B}}\right)$ and the experimental data points for all prepared samples of the $\mathrm{C}_{x} \mathrm{E}_{y}$ series.

The derivation of this model, which is a quantitative description of the three phase situation, is given in the following section.

3.2. Physical Approach toward the Three-Phase Model. To derive a model that relates the aggregation of the $\mathrm{C}_{x} \mathrm{E}_{y}$ surfactants to the porosity, we follow the work of Antonietti and Förster on the micellization of different types of amphiphiles. $^{54,55}$ In particular, the radius of micelles was related to the block lengths of nonionic surfactants in these studies. On the basis of the conservation of the overall volume of the surfactant and the interface that is stabilized, an expression was obtained for the aggregation number $Z$ of the micelles, which is directly related to the micelle radius (and to a hypothetical corresponding pore radius).

$$
\begin{aligned}
& Z \propto N_{\mathrm{A}}{ }^{193} N_{\mathrm{B}}^{-079} \\
& R_{\mathrm{c}} \propto N_{\mathrm{A}}{ }^{097} N_{\mathrm{B}}{ }^{-04}
\end{aligned}
$$

Although this model also predicts the micelle (mesopore) size to be dependent on the hydrophilic block $N_{\mathrm{B}}$, a comparison with the previously mentioned empirical relationship between $D_{\mathrm{c}}$ and $N_{\mathrm{A}}, N_{\mathrm{B}}$ obtained for the $\mathrm{C}_{x} \mathrm{E}_{y}$ surfactants clearly shows that a modified approach other than the rules describing micelle formation is needed to explain the behavior under nanocasting conditions.

In particular, the approach of Förster et al. and Antonietti et al. is not applicable to describe the nanocasting mechanism due to the fact that the PEO chains probably do not form a homogeneous corona surrounding the hydrophobic core during the templating step. Instead, a certain fraction of the PEO chains is molecularly embedded in the silica matrix (phase III), while the rest of PEO (phase II) is situated between the hydrophobic core (phase I) and the silica.

A model of the three-phase situation is given in Figure 7, where a slice from a cylindrical object is assumed to describe the lyotropic phase.

Moreover, it is to be expected that a dense or highly concentrated system behaves differently than the dilute micellar solutions used in the studies of Förster et al. This is especially true for the fact that solvation or entropic forces is less important for dense systems, whereas packing consideration gains more

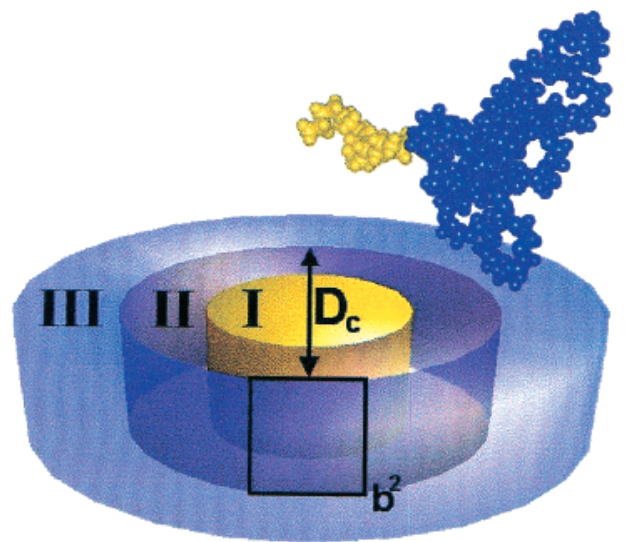

Figure 7. Schematic representation of the three-phase model. $\mathrm{A} \mathrm{C}_{x} \mathrm{E}_{y}$ surfactant, shown as a molecular-modeling image, is divided into the three phases: (I) hydrophobic domain, (II) PEO domain located in the mesopore volume, and (III) PEO domain located in the micropore volume.

importance. Therefore, it has to be expected that the inner block gains more importance on the aggregation behavior.

Taking into account the geometry of a cylinder (which we assume to approximate the wormlike structure best), the interface area $A_{\text {int }}$ and the overall volume $V$ are given by

$$
\begin{gathered}
A_{\text {int }}=2 \pi R_{\mathrm{c}} b=Z b^{2} \\
V=\pi R_{\mathrm{c}}^{2} b=\left[N_{\mathrm{A}} a^{3} Z\right]_{\mathrm{I}}+\left(\left[N_{\mathrm{B}}-[C]_{\mathrm{III}}\right]_{\mathrm{II}} V_{\mathrm{b}} Q Z\right)
\end{gathered}
$$

$b^{2}$ is the area occupied by one surfactant molecule at the interface between the hydrophobic core and the aqueous medium, $a^{3}$ denotes the volume of the alkyl unit in the hydrophobic chain (in conformity with the nomenclature of Bates), ${ }^{56}$ and $V_{\mathrm{b}}$ denotes the volume of a single molecule of the amphiphile.

Equation 5 describes the conservation of the total volume in the three-phase system. The term labeled I is related to the volume contributed by the hydrophobic chains. The additional parameter $Q$ describes possible swelling of the PEO chains with $\mathrm{H}_{2} \mathrm{O}$. As an approximation it is assumed that $Q$ is constant in 
both phases II and III although in reality their might be a $Q_{\mathrm{II}}$ and a $Q_{\mathrm{III}}$ that differ. The hydrophilic PEO chains are separated between two phases, one contributing to the mesopore core (phase II) and the second located in the silica wall and creating microporosity (phase III) as described by the parameter $C$. The mesopore size $D_{\mathrm{c}}$ is determined by phases I and II. From eq 4 we obtain

$$
Z=\frac{2 \pi R_{\mathrm{c}}}{b}
$$

By insertion of (6) into (5) it follows

$$
D_{\mathrm{c}}=\frac{4\left[N_{\mathrm{A}} a^{3}+\left(N_{\mathrm{B}}-C\right) Q V_{\mathrm{b}}\right]}{b^{2}}
$$

Equation 7 relates the mesopore size to the volume of the single blocks. Because of the fact that a lyotropic phase represents a dense system (in our case the concentration of amphiphile was 50 wt $\%$ in water), we have to drop the assumption ${ }^{54}$ that the interface area per surfactant $b^{2}$ does not depend on $N_{\mathrm{A}}$ but is set as a scaling law:

$$
b^{2}=b_{0}^{2} N_{\mathrm{A}}^{\alpha} N_{\mathrm{B}}^{\beta}
$$

$b_{0}^{2}$ is just a unit-surface area to obey dimensional requirements. By insertion of (5) in (4) it follows

$$
D_{\mathrm{c}}=\frac{4\left[N_{\mathrm{A}} a^{3}+\left(N_{\mathrm{B}}-C\right) V_{b} Q\right]}{b_{0}{ }^{2} N_{\mathrm{A}}{ }^{\alpha} N_{\mathrm{B}}{ }^{\beta}}
$$

After some rearrangements one ends up with

$$
D_{\mathrm{C}}=\left[\frac{4 V_{\mathrm{A}} N_{\mathrm{A}}}{b_{0}^{2} N_{\mathrm{A}}^{\alpha} N_{\mathrm{B}}^{\beta}}\right]_{\mathrm{I}}+\frac{4 Q V_{\mathrm{B}}}{b_{0}^{2}}\left(\left[\frac{N_{\mathrm{B}}}{N_{\mathrm{A}}^{\alpha} N_{\mathrm{B}}^{\beta}}\right]_{\mathrm{II}}-\left[\frac{C}{N_{\mathrm{A}}^{\alpha} N_{\mathrm{B}}^{\beta}}\right]_{\mathrm{III}}\right)
$$

Indices I-III refer to the contributions of the hydrophobic and hydrophilic parts to the mesopore radius. Hence, the "threephase model" can be described reasonably, providing a basic relationship between the diameter of the mesopore and the block lengths of the surfactants used as the template. The theoretical approach indicates that the distribution of the PEO chains has a significant influence on the size of the mesopores. It is therefore necessary to evaluate the quantity $C$, the number of PEO chains embedded in the silica matrix (phase III), which can be done by a determination of the microporosity resulting from these PEO chains. As a consequence, in the following we focus on the determination of the microporosity (comprised in the parameter $C$ in eq 10), from which a semiquantitative description of the "three-phase model" can be derived. By insertion of this experimental result, eq 10 will be directly related to the mesopore sizes.

We applied the SAXS technique to determine the microporosity and checked the measurement by $\mathrm{N}_{2}$ sorption ultralowpressure analysis. The results are given in Table 2 .

The data indicate that the silicas indeed contain a substantial degree of microporosity (even up to $80 \%$ of the total specific surface area can be caused by the micropores). This porosity has to be attributed to phase III. Since the size of the micropores is below $1 \mathrm{~nm}$, the corresponding micropore volume is significantly lower than the mesopore volume. The observed microporosity is created exclusively by the PEO chains due to the observation that a silica material that was also prepared at
Two phase system

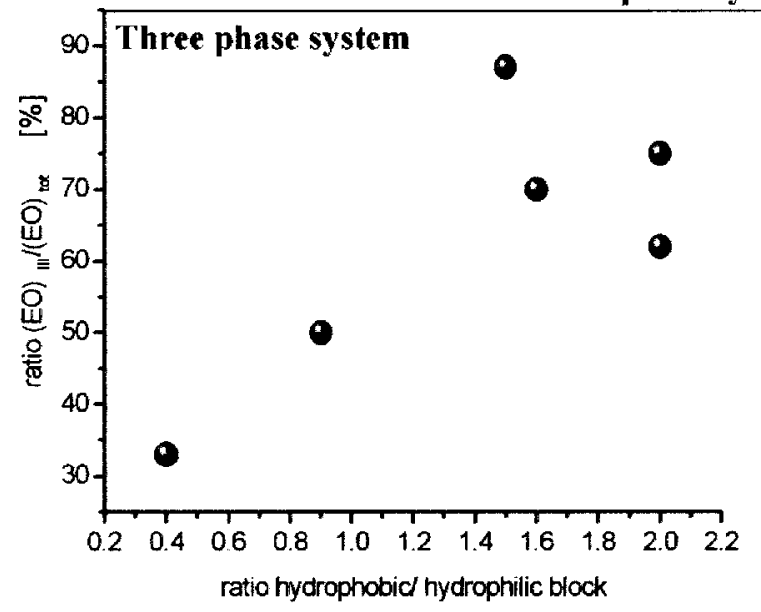

Figure 8. Ratio of amount of EO units located in the micropore volume (phase III) divided by the total amount of EO units per amphiphile molecule plotted against the ratio of the hydrophobic block divided by the hydrophilic block $\left(N_{\mathrm{A}} / N_{\mathrm{B}}\right)$. In the region where $N_{\mathrm{A}} / N_{\mathrm{B}}$ is small a three-phase situation is realized (only a small relative amount of PEO is located in phase III, while a large amount contributes to the mesopore volume). Only for high values of $N_{\mathrm{A}} / N_{\mathrm{B}}$ is a two-phase situation realistic.

TABLE 3: Micropore Volumes Created by the EO Units per Amphiphile That Are Located in the Third Phase

\begin{tabular}{lccc}
\hline $\begin{array}{c}\text { micropore vol }\left(V_{\text {micro }}\right) \\
\text { silica } \\
\text { sample }\end{array}$ & $\begin{array}{c}\text { amphiphile } \\
\text { amphile }\end{array}$ & $\begin{array}{c}\text { no. of EO units } \\
\text { in phase III (in the } \\
\text { silica matrix })\end{array}$ & $\begin{array}{c}\text { rel amt } \\
\left(10^{-23} \mathrm{~cm}^{-3}\right)\end{array}$ \\
\hline $\mathrm{C}_{8} \mathrm{E}_{4}$ & 5 & 3 & 0.75 \\
$\mathrm{C}_{12} \mathrm{E}_{8}$ & 12 & 7 & 0.87 \\
$\mathrm{C}_{16} \mathrm{E}_{8}$ & 10 & 5 & 0.63 \\
$\mathrm{C}_{16} \mathrm{E}_{10}$ & 12 & 7 & 0.70 \\
$\mathrm{C}_{18} \mathrm{E}_{20}$ & 18 & 10 & 0.50 \\
$\mathrm{C}_{12} \mathrm{E}_{30}$ & 18 & 10 & 0.33
\end{tabular}

$\mathrm{pH}=2$ but when no template was present is practically nonporous. These results are in reasonable agreement with the findings of Göltner et al. and provide a further indication of the microporous character of silicas obtained from the templating of lyotropic phases of PEO containing block copolymers. ${ }^{29}$ Second, the experimental data in Table 2 also show certain trends concerning the degree of microporosity as a function of the relative block lengths. For instance, the contribution of micropores to the overall specific surface area is substantially lower for the $\mathrm{C}_{12} \mathrm{E}_{30}$ silica compared to the $\mathrm{C}_{8} \mathrm{E}_{4}$ silica despite the larger PEO block. This is consistent with the assumption that a significant fraction of the $\mathrm{EO}$ units in $\mathrm{C}_{12} \mathrm{E}_{30}$ contributes to mesoporosity and not to microporosity according to the "three-phase model".

To relate the micropore volume to a real number of EO units located in the silica wall (phase III), we also templated (using the nanocasting under identical conditions) pure PEO as a reference and determined the micropore volume via the combination of nitrogen sorption and SAXS. The raw data can also be obtained from the study of Göltner et al. ${ }^{29}$ The micropore volume created by one EO unit in the nanocasting procedure was found to be approximately $\approx 2 \times 10^{-23} \mathrm{~cm}^{3}$. With this value and the micropore volumes in Table 2, the data in Table 3 are obtained.

The data show a significant trend with regard to the amount of PEO being embedded in the silica matrix and, thus, leading to microporosity. For instance, in the case of $\mathrm{C}_{8} \mathrm{E}_{4}$ a considerably higher portion of PEO chains is situated in the silica wall than for $\mathrm{C}_{12} \mathrm{E}_{30}$. However, this is not true for the absolute number 

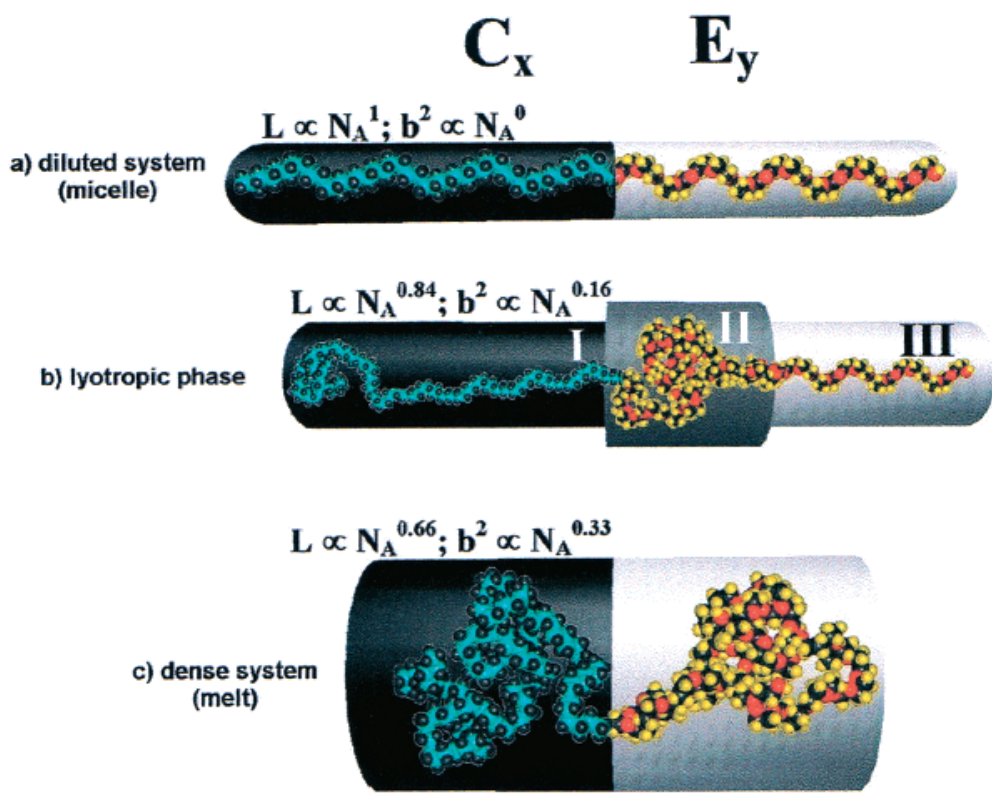

Figure 9. Schematic representation of the scaling relations for the two extreme cases block copolymer melt and block copolymer micelle as well as the via nanocasting studied case of a lyotropic phase. The three-phase situation in the PEO block is also indicated.

of units embedded: The longer the PEO block, the more PEO is bound in the silica wall. With increasing length of the hydrophobic block, a larger interface has to be stabilized, and more PEO is transferred to phase III (see Figure 7). In cases where the hydrophobic block is relatively large compared to the hydrophilic block, nearly all the PEO is located in the silica matrix, for example, in the case of the $\mathrm{C}_{8} \mathrm{E}_{4}$ silica. A visualization of these tendencies is obtained by plotting the relative amount of PEO units located in phase III against the block ratio (hydrophobic/hydrophilic block) (Figure 8).

These experiments enable an estimation of the dependence of the parameter $C$ upon $N_{\mathrm{A}}$ and $N_{\mathrm{B}}$. Taking into account the limited number of data points, the data showed a linear relationship $C=\left(\tilde{k}_{\mathrm{A}} N_{\mathrm{A}}+\tilde{k}_{\mathrm{B}} N_{\mathrm{B}}\right)$. A fit of the experimental data (Table 3) reveals $\tilde{k}_{\mathrm{A}}=0.26$ and $\tilde{k}_{\mathrm{B}}=0.24$.

Since the ratios $V_{\mathrm{B}} / b_{0}^{2}$ and $V_{\mathrm{A}} / b_{0}^{2}$ can be estimated from the geometry of the surfactant, two "constrained" parameters $K_{\mathrm{I}}=$ $2 V_{\mathrm{A}} / b_{0}^{2}$ and $K_{\mathrm{II}}=\left(2 V_{\mathrm{B}} / b_{0}^{2}\right) Q$ are introduced, resulting in the following expression that describes the mesopore size $D_{\mathrm{C}}$ as a function of $N_{\mathrm{A}}$ and $N_{\mathrm{B}}$.

$$
\begin{aligned}
D_{\mathrm{C}}=2\left\{K_{\mathrm{I}}\left[\frac{N_{\mathrm{A}}}{N_{\mathrm{A}}^{\alpha} N_{\mathrm{B}}^{\beta}}\right]_{\mathrm{I}}+\right. \\
\left.K_{\mathrm{II}}\left(\left[\frac{N_{\mathrm{B}}}{N_{\mathrm{A}}^{\alpha} N_{\mathrm{B}}^{\beta}}\right]_{\mathrm{II}}-\left[\frac{0.26 N_{\mathrm{A}}+0.24 N_{\mathrm{B}}}{N_{\mathrm{A}}^{\alpha} N_{\mathrm{B}}^{\beta}}\right]_{\mathrm{III}}\right)\right\}
\end{aligned}
$$

Fitting the experimental data with eq 11 provides the parameters $\alpha=0.16$ and $\beta=0.4$ (with $K_{\mathrm{I}}=0.5 \mathrm{~nm}, K_{\mathrm{II}}=0.9$ $\mathrm{nm}$ ). Due to the (restricted) description of the curve, the standard deviation of these parameters is of the order of up to $20 \%$. However, the values obtained from the fit of eq 11 using the DFT data are physically reasonable and fully consistent with the underlying "three-phase model". For instance, the slightly higher value of $K_{\mathrm{II}}$ compared to $K_{\mathrm{I}}$ reflects the fact that the hydrated EO monomer unit occupies are larger volume than a $\mathrm{CH}_{2}$ monomer group.

A variable interface area $b^{2}$ and values for $\alpha$ and $\beta$ are already known for two other systems. ${ }^{56}$ One extreme case is the state of the surfactants in dilute solution and the other extreme is represented by the melt (dense system). Förster et al. found a relationship of $b^{2}=b_{0}{ }^{2} N_{\mathrm{A}}{ }^{0} N_{\mathrm{B}}{ }^{27}$ for dilute solutions of these amphiphiles. ${ }^{55} b^{2}$ is fully independent of $N_{\mathrm{A}}$, and the hydrophobic chain is in a stretched state. The higher dependence of the interface area per molecule on both block or tail lengths as observed in our study is already known from block copolymer melts. In this case, both exponents are of the order of 0.33 for close to symmetric systems. ${ }^{56}$ This is regarded as typical for systems where chain entropy and packing considerations dominate the polymer-solvent interactions. In the case of a block copolymer melt, $b^{2}$ is a proportional of $N_{\mathrm{A}}{ }^{033}$ while the length of the hydrophilic chain scales with $L \propto N_{\mathrm{A}}{ }^{066}$. Note that in all cases because of density conservation the volume has to go with $V \propto L b^{2} \propto N_{\mathrm{A}}$. In a dense situation like this the hydrophobic chain is found to exist in a rather coiled state (similar to the Gaussian random coil $L \propto N_{\mathrm{A}}{ }^{05} ; b^{2} \propto N_{\mathrm{A}}{ }^{05}$ ). The found scaling exponents $b^{2}=b_{0}^{2} N_{\mathrm{A}}{ }^{016 \pm 0} 03 N_{\mathrm{B}}{ }^{040 \pm 008}$ mean that the hydrophobic, densely packed chain is more stretched ( $L \propto N_{\mathrm{A}}{ }^{084}$, which is a little less than the Förster case of a dilute micellar solution), whereas the hydrophilic chain form is in a swollen and only slightly stretched conformation $(L \propto$ $N_{\mathrm{A}}{ }^{06}$ ), which goes well with the expectations of a concentrated lyotropic phase. This is schematically demonstrated in Figure 9.

In a lyotropic phase as depicted by the nanocasting the situation is located between of the two mentioned, extreme cases. It should be mentioned that $D_{\mathrm{c}}$, the mesopore diameter, needs not directly correlate to $2 L$ (see Figure 9) due to interdigitation of the cylinder volumes relative to each other.

As a final result, the dependence of the pore diameter $D_{\mathrm{c}}$ on both chain lengths (Figures 6 and 7) is not only empirically described by the relation (eq 11), but is also based on a simple model describing the chain conformation of a single surfactant molecule in its assembly expressed via the scaling relation in eq 8 .

3.3. Influence of Mixtures of Amphiphiles. Since the mesopore size reflects the size and shape of the surfactant aggregate, it should also be possible to use silica nanocasting to study the mixing rules of micellar aggregation. Vice versa, the mixing of different surfactant homologues is then expected 
SAXS from silicas obtained from mixtures of

SE1010 and SE3030

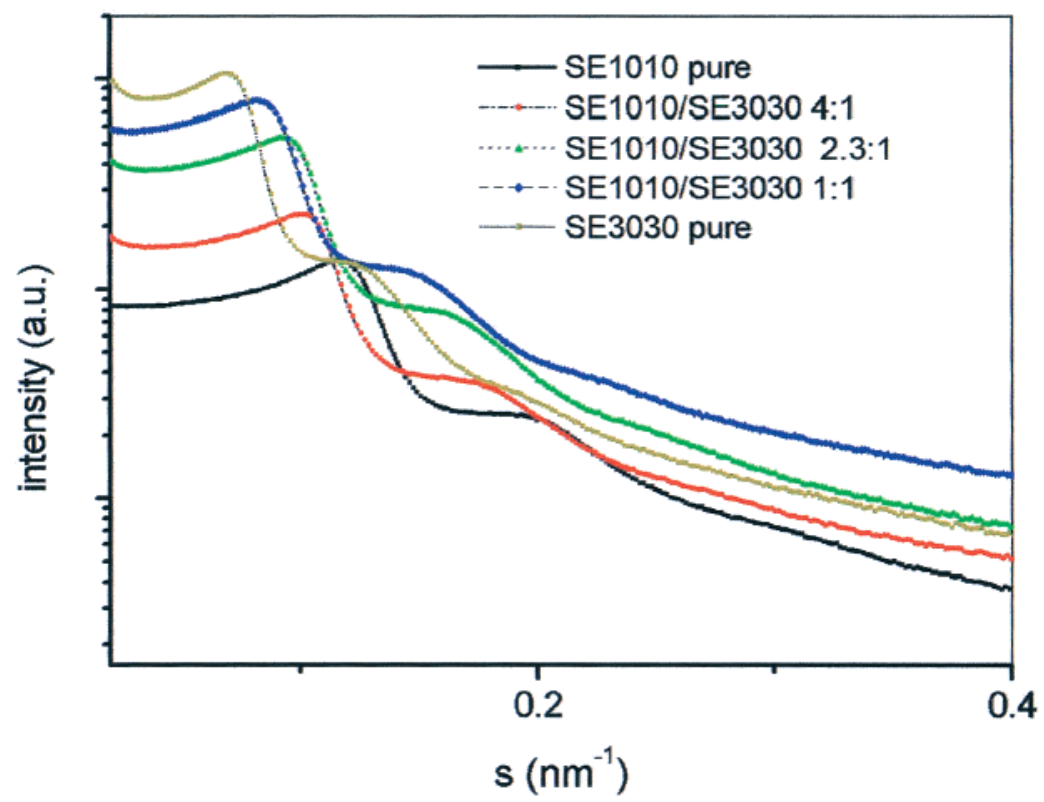

Figure 10. SAXS data of SE-based silica materials.

TABLE 4: Size of the Mesopores of Silicas Obtained from Mixtures of SE1010 and SE3030 by Nitrogen Sorption Analysis ${ }^{a}$

\begin{tabular}{llllll}
\hline mixture & SE1010 pure & SE1010/SE3030 4:1 & SE1010/SE3030 2.3:1 & SE1010/SE3030 1:1 & SE3030 pure \\
mesopore diameter (nm) (DFT) & 4.8 & 7.0 & 8.3 & 9.0 & 9.5 \\
$d$ spacing from SAXS (nm) & 8.3 & 9.8 & 10.8 & 11.9 & 14.3
\end{tabular}

${ }^{a}$ The mixing ratio is referred to the mass of the polymers used in the recipe.

to allow fine adjustment of the mesopore size in the ångstrom range by simple stoichiometry. This, however, is based on the assumption that homogeneous mixing occurs on the micellar scale and results in micelles with similar geometry or architecture (i.e., no new phase structures appear).

This assumption was found to be fulfilled for practically all used $\mathrm{C}_{x} \mathrm{E}_{y}$ 1:1 surfactant mixtures (see Table 1). Only in one case was an unexpectedly large mesopore size for the mixture found. The pore size of the silica obtained from mixtures of $\mathrm{C}_{x} \mathrm{E}_{y}$ surfactants of different block lengths lies between the pore sizes of both pure surfactants for all cases (see Table 1).

Figure 6 also contains the data obtained from various 1:1 mixtures. By using different amounts of surfactants every pore size between the "parent" materials can be adjusted. The size of the resulting silica pore is given by eq 11 or the surface in Figure 6, where the values for $N_{\mathrm{A}}$ and $N_{\mathrm{B}}$ are derived as an average of the parent compounds. It is seen that the data are well described when the molar incidences of the different templates (in all cases 1:1 mixtures of masses were taken, which means that the molar amounts differ quite much) are taken into account. Still, the larger hydrophobic block in the mixture is more decisive for the mesopore size according to the empirically obtained $N_{\mathrm{A}}{ }^{04}$ dependence of $D_{\mathrm{c}}$. Furthermore, it turned out that the derived structures are true equilibrium situations that are highly unattached by experimental conditions. Our experiments showed that the pore size can be adjusted nearly on an ångstrom scale. It has to be pointed out that even for mixtures of $\mathrm{C}_{12}$ and $\mathrm{C}_{16}$ significant and reproducible differences for pore sizes in the region of only about $0.1 \mathrm{~nm}$ have been observed.

To test the validity of our model, we extended our experiments to different block copolymer systems also leading to "worm-type" silica materials. Göltner et al. have used poly- (styrene)-poly(ethylene oxide) ("SE") block copolymers for the preparation of "worm-type" porous silica materials. ${ }^{19}$ Two polymers with short poly(styrene) and poly(ethylene oxide) blocks ("SE1010", $M_{\mathrm{w}}=1000$ for both blocks, respectively) and longer blocks ("SE3030", $M_{\mathrm{w}}=300$ for both blocks, respectively) have been used. Unfortunately, the polydispersity of these SE-type polymers is quite large, and a sufficient variety of block copolymers was not accessible for establishing a similar set of experiments to derive the quantitative relationship between the mesopore sizes and the block lengths, as in the case of the $\mathrm{C}_{x} \mathrm{E}_{y}$-based silicas. However, the procedure to control the pore sizes by mixing of SE polymers turned out to be a suitable strategy also for SE templates. It was found that the pore size can be adjusted to every value between $5 \mathrm{~nm}$ (pure SE1010 silica) and $10.5 \mathrm{~nm}$ (pure SE3030 silica), which is illustrated in Figure 10 and Table 4.

Figure 10 contains SAXS patterns of SE-based silica that were obtained by mixing SE1010 and SE3030. First, the position of the main interference peak is continuously shifted between the positions of the two pure SE1010-derived material and SE3030derived material. Second, the first minimum of the scattering curve, which can be related to the mesopore size, is successively shifted to smaller scattering vectors (compared to SE1010 silica) with an increasing content of SE3030. Moreover, the data indicate that the larger block copolymer has a stronger influence (higher statistical weight) on the mesopore sizes, as was also found for the $C_{x} E_{y}$ silicas, however for a much smaller range of variations.

\section{Conclusion}

The study presented in this paper was aimed at a more detailed understanding of the nanocasting approach for creating 
mesoporous silica structures by templating lyotropic phases of nonionic block copolymer systems. By using the well-known "Brij" surfactants $\left(\mathrm{C}_{x} \mathrm{E}_{y}\right)$, the influence of the length of both the alkyl chain and the poly(ethylene oxide) chain on the porosity was investigated by a combination of nitrogen sorption and small-angle X-ray scattering (SAXS). Suitable evaluation methods of the SAXS data also allowed us to estimate the content of micropores arising from a molecular templating of the PEO chains.

It was found that the size of the mesopores depends both on the length $N_{\mathrm{A}}$ of the hydrophobic block and on the length $N_{\mathrm{B}}$ of the hydrophilic block. An empirical dependence for the relationship between the mesopore size and the block lengths was found and could be reasonably explained by a simple geometrical model ("three-phase model") previously introduced by Göltner et al. ${ }^{29}$ Our data indicated that the PEO contributes both to microporosity and also partially to the mesopore volume, the relation of which was quantified and shown to depend on the surfactant structure in a systematic fashion. With this knowledge, not only pore size but also the relative contributions of micro- and mesoporosity can be predicted and adjusted in a certain range independently from each other.

To connect the experimentally found empirical scaling relation between pore size and pore diameter with the "threephase model", a single relationship describing the conformation of the surfactant along the hydrophobic/hydrophilic interface was related to the mesopore diameters. We found for the interface area per molecule $b^{2}=b_{0}{ }^{2} N_{\mathrm{A}}{ }^{016} N_{\mathrm{B}}{ }^{04}$, which is between the behavior of block copolymers in the melt and in a dilute micellar system. Our findings are in good agreement with a slightly extended statistical chain conformation of the surfactant. From our results we also have to draw the conclusion that the mesopore size and its dependence on $N_{\mathrm{B}}$ is not just caused by interface effects in a two-phase system but that a third phase (PEO between hydrophobic core and silica matrix) is real. Therefore, the question arises if the nanocasting just solidifies the lyotropic phase, which would mean that a lyotropic phase of a nonionic block copolymer also contains three phases. One phase is the hydrophobic domain. The hydrophilic domain is further microphase-separated into a dense phase including only minor amounts of solvent (during the sol-gel process the solvent equals water plus silicic acid), thus causing an enlargement of the mesopore volume, and a phase that is really dispersed in the solvent and thus causes the microporosity.

Moreover, our results suggest that the soft-matter structures solidified by the nanocasting are true equilibrium structures. Variations of the experimental procedure have no significant effect, as shown by a high reproducibility and mutual comparability of the data. It can be concluded that the silica nanocasting is also a suitable analysis technique to depict even small differences in soft-matter structures in solution with a resolution on an ångstrom scale.

It was also shown that mixtures of amphiphilic block copolymers lead to a true mixed lyotropic phase. The values of the aggregate or corresponding mesopore sizes turned out to be between the corresponding samples obtained from single block copolymers. The intermediate pore size is mainly determined by the block copolymer with the longer hydrophobic chain. Our experiments suggest that every pore size between the boundaries given by the "parent" compounds can be adjusted by a suitable ratio of templates.

Further work in this field will address the evolution of the microporosity and the mesopore sizes as a function of other factors such as the temperature or electrolyte concentration.
Concerning mixtures of block copolymers, it would be interesting to study mixtures of chemically different template systems to template also self-assembly structures at the borderline of demixing.

Acknowledgment. The Max-Planck society is gratefully acknowledged for funding. We also thank Prof. F. Schüth and Dr. W. Schmidt from the Max-Planck Institute for ColeResearch for their assistance in the ultralow-pressure measurements.

\section{References and Notes}

(1) Beck, J. S.; Vartuli, J. C.; Roth, W. J.; Leonowicz, M. E.; Kresge, C. T.; Schmitt, K. D ; Chu, C. T ; Olson, D. H.; Sheppard, E. W.; McCullen, S. B.; Higgins, J. B.; Schlenker, J. L. J. Am. Chem. Soc. 1992, 114, 1083410843

(2) Kresge, C. T.; Leonowicz, M.; Roth, W. J.; Vartuli, J. C.; Beck, J. S. Nature 1992, 359, 710.

(3) Raman, N. K ; Anderson, M. T.; Brinker, C. J. Chem. Mater. 1996, 8, 1682-1701.

(4) Beck, J. S.; Vartuli, J. C. Curr. Opin. Solid State Mater. Sci. 1996, $1,76-87$.

(5) Barton, T. J.; Bull, L. M.; Klemperer, W. G.; Loy, D. A. McEnaney, B.; Misono, M ; Monson, P. A.; Pez, G.; Scherer, G. W.; Vartuli, J. C.; Yaghi, O. M. Chem. Mater. 1999, 11, 2633-2656.

(6) Hüsing, N.; Schubert, U. Angew. Chem. 1998, 110, 22-47.

(7) Möller, K.; Bein, T. Chem. Mater. 1998, 10, 2950-2963.

(8) Schüth, F. Chem. Z. 1995, 29, 42

(9) Polarz, S.; Smarsly, B.; Göltner, C.; Antonietti, M. Adv. Mater. 2000, 12, 1503-1507.

(10) Ying, J. Y.; Mehnert, C. P.; Wong, M. S. Angew. Chem. 1999, 38, $58-82$.

(11) Shüth, F.; Stucky, G. D.; et al. Nature 1994, 368, 317.

(12) Stucky, G. D.; Chmelka, B. F. Nature 1995, 267, 1138

(13) Stucky, G. D.; Chmelka, B. F.; Schüth, F.; et al. Science 1993 261,1299

(14) Attard, G. S.; Glyde, J. G.; Göltner, C. G. Nature 1995, 378, 366

(15) Göltner, C. G.; Berton, B.; Krämer, E.; Antonietti, M. Adv. Mater 1999, 11, 395

(16) Göltner, C. G.; Berton, B.; Krämer, E.; Antonietti, M. Chem. Commun. 1998, 2287-2288.

(17) Göltner, C. G.; Antonietti, M. Adv. Mater. 1997, 9, 431.

(18) Weissenberger, M. C.; Göltner, C. G.; Antonietti, M. Ber. BunsenGes. Phys. Chem. 1997, 101, 1679-1682.

(19) Göltner, C. G.; Henke, S.; Weissenberger, M. C.; Antonietti, M. Angew. Chem. 1998, 110, 633.

(20) Feng, P.; Bu, X.; Stucky, G. D.; Pine, D. J. J. Am. Chem. Soc. 2000, 122, 994-995.

(21) Melosh, N. A.; Lipic, P.; Bates, F. S.; Wudl, F.; Stucky, G. D. Fredrickson, G. H.; Chmelka, B. F. Macromolecules 1999, 32, 4332-4342.

(22) Rouqerol, J.; Avnir, D.; Fairbridge, C. W.; Everett, D. H.; Haynes, J. H.; Pernicone, N.; Ramsay, J. D.; Sing, K. S. W.; Unger, K. K. Pure Appl. Chem. 1994, 66, 1739-1758.

(23) Sing, K. S. W.; Everett, D. H.; Haul, R. A. W.; Moscou, L ; Pierotti, R. A.; Rouquérol, J.; Siemieniewska, T. Pure Appl. Chem. 1985, 57, 603619 .

(24) Göltner, C. G.; Smarsly, B.; Berton, B.; Antonietti, M. Chem. Mater. 2000, 13, 1617-1624.

(25) Myazawa, K.; Inagaki, S. Chem. Commun. 2000, 2121.

(26) Jaroniec, M.; Kruk, M.; Ko, C. H.; Ryoo, R. Chem. Mater. 2000, 12,1961 .

(27) Ryoo, R.; Ko, C. H.; Kruk, M.; Antochshuk, V.; Jaroniec, M. J. Phys. Chem. B 2000, 104, 11465.

(28) Paul, S. M. D.; Zwanziger, J. W.; Ulrich, R.; Wiesner, U.; Spiess, H. W. J. Am. Chem. Soc. 1999, 121, 5727

(29) Göltner, C. G.; Smarsly, B.; Berton, B.; Antonietti, M. Chem. Mater., in press.

(30) Kim, S.; Pauly, T. R.; Pinnavaia, T. J. Chem. Commun. 2000, 16611662 .

(31) Tanev, P. T.; Pinnavaia, T. J. Science 1995, 267, 865-867.

(32) Kim, S.; Pauly, T. R.; Pinnavaia, T. J. Chem. Commun. 2000, 835836.

(33) Bagshaw, S. A.; Prouzet, E.; Pinnavaia, T. J. Science 1995, 269, $1242-1244$.

(34) Prouzet, E.; Pinnavaia, T. J. Angew. Chem. 1997, 109, 533-536.

(35) Schacht, S.; Huo, Q.; Voigt-Martin, I. G.; Stucky, G. D.; Schüth, F. Science 1996, 273, 769 .

(36) Lettow, J. S.; Han, Y. J.; Schmidt-Winkel, P.; Yang, P.; Zhao, D.; Stucky, G. D.; Ying, J. Y. Langmuir 2000, 16, 8291-8295. 
(37) Mering, P. J.; Tchoubar, D. J. Appl. Crystallogr. 1968, 1, 153.

(38) Mering, J.; Tchoubar, D. C. R. Hebd. Seances Acad. Sci. Ser. B 1966, 262, 1703.

(39) Mering, J.; Tchoubar, D. C. R. Hebd. Seances Acad. Sci. 1965, 261, 3096.

(40) Porod, G. Kolloid Z. Z. Polym. 1951, 124, 83.

(41) Porod, G. Kolloid Z. Z. Polym. 1952, 125, 51.

(42) Porod, G. Kolloid Z. Z. Polym. 1952, 125, 108.

(43) Ciccariello, S. Acta Crystallogr. Sect. A 1993, 49, 398-405.

(44) Ciccariello, S.; Benedetti, A. Phys. Rev. B 1982, 26, 6384-6389.

(45) Ciccariello, S.; Cocco, G.; Benedetti, A.; Enzo, S. Phys. Rev. B 1981, 23, 6474-6485.

(46) Smarsly, B.; Goltner, C.; Antonietti, M.; Ruland, W.; Hoinkis, E. J. Phys. Chem. B 2001, 105, 831-840.

(47) Mitchell, D. J.; Tiddy, G. J. T.; Waring, L.; Bostock, T ; McDonald,

M. P. J. Chem. Soc., Faraday Trans. 1983, 79, 975-1000.
(48) Ravikovitch, P. I.; Haller, G. L.; Neimark, A. V. Adv. Colloid Interface Sci. 1998, 76-77, 203-226.

(49) Ravikovitch, P. I.; Wei, D.; Chueh, W. T.; Haller, G. L.; Neimark, A. V. J. Phys. Chem. B 1997, 101, 3671-3679.

(50) Neimark, A. V.; Ravikovitch, P. I. Langmuir 1997, 13, 5148-5160. (51) Olivier, J. P.; Occelli, M. L. J. Phys. Chem. B 2001, 105, 623629.

(52) Olivier, J. P. Carbon 1998, 36, 1469-1472.

(53) Gregg, S. J.; Sing, K. S. W. Adsorption, Surface Area and Porosity, 4th ed.; Academic Press: New York, 1982; Vol. 2.

(54) Antonietti, M ; Heinz, S.; Schmidt, M.; Rosenauer, C. Macromolecules 1994, 27, 3276.

(55) Förster, S.; Zisenis, M.; Wenz, E.; Antonietti, M. J. Chem. Phys. 1996, 104, 9956.

(56) Bates, F. S.; Fredrickson, G. H. Annu. Rev. Phys. Chem. 1990, 41, $525-557$. 